\title{
Investigations on Diamond Nanostructuring of Different Morphologies by the Reactive-Ion Etching Process and Their Potential Applications
}

\author{
Srinivasu Kunuku, ${ }^{\dagger}$ Kamatchi Jothiramalingam Sankaran, ${ }^{\ddagger}$ Cheng-Yen Tsai, ${ }^{\S}$ Wen-Hao Chang, ${ }^{\S}$ \\ Nyan-Hwa Tai, Keh-Chyang Leou, ${ }^{\ddagger}, \dagger$ and I-Nan Lin ${ }^{*}, \mathscr{I l}$ \\ ${ }^{\dagger}$ Department of Engineering and System Science, National Tsing Hua University, Hsinchu 300, Taiwan, Republic of China \\ ${ }^{\ddagger}$ Department of Materials Science and Engineering, National Tsing Hua University, Hsinchu 300, Taiwan, Republic of China \\ ${ }^{\S}$ Department of Electrophysics, National Chiao Tung University, Hsinchu 300, Taiwan, Republic of China \\ ${ }^{I}$ Department of Physics, Tamkang University, Tamsui 251, Taiwan, Republic of China
}

\section{Supporting Information}

\begin{abstract}
We report the systematic studies on the fabrication of aligned, uniform, and highly dense diamond nanostructures from diamond films of various granular structures. Self-assembled Au nanodots are used as a mask in the self-biased reactive-ion etching (RIE) process, using an $\mathrm{O}_{2} / \mathrm{CF}_{4}$ process plasma. The morphology of diamond nanostructures is a close function of the initial phase composition of diamond. Cone-shaped and tip-shaped diamond nanostructures result for microcrystalline diamond (MCD) and nanocrystalline diamond (NCD) films, whereas pillarlike and grasslike diamond nanostructures are obtained for Ar-plasma-based and $\mathrm{N}_{2}$-plasma-based ultrananocrystalline diamond (UNCD) films, respectively. While the nitrogen-

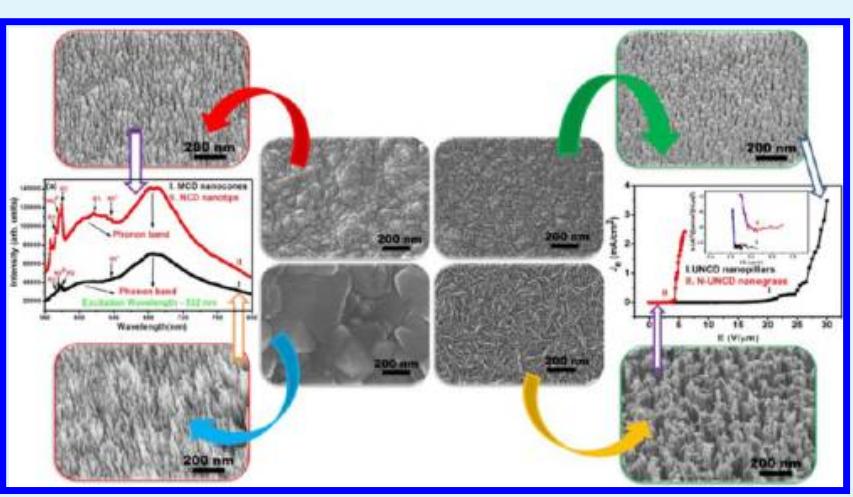
incorporated UNCD (N-UNCD) nanograss shows the most-superior electron-field-emission properties, the NCD nanotips exhibit the best photoluminescence properties, viz, different applications need different morphology of diamond nanostructures to optimize the respective characteristics. The optimum diamond nanostructure can be achieved by proper choice of granular structure of the initial diamond film. The etching mechanism is explained by in situ observation of optical emission spectrum of RIE plasma. The preferential etching of $\mathrm{sp}^{2}$-bonded carbon contained in the diamond films is the prime factor, which forms the unique diamond nanostructures from each type of diamond films. However, the excited oxygen atoms $\left(\mathrm{O}^{*}\right)$ are the main etching species of diamond film.
\end{abstract}

KEYWORDS: diamond nanostructures, reactive ion etching, Au nanodots, ion bombardment, electron field emission, photoluminescence

\section{INTRODUCTION}

One-dimensional (1D) nanostructures attract enormous interest in the field of optoelectronic devices and chemical and biochemical sensors, because of their high aspect ratio and low dimensional effect. ${ }^{1-5}$ The robust applications of materials are not only a function of the bulk intrinsic properties but also a function of their surface activities. Diamond is an exclusive material for potential applications such as biological and chemical sensors, microelectromechanical devices, electron field emitters, and single photon sources, because of its wide band gap, highest hardness, outstanding thermal conductivity, tunable negative electron affinity, and virtuous chemical inertness. $^{6-9}$ Meanwhile, diamond nanostructuring is an effective method for improving these peculiar properties.

Among the potential applications of diamond nanostructures, electron field emitters and single photon source are the most promising ones. The electron field emitters have great potential in the development of vacuum electronic devices such as traveling wave tubes, portable $\mathrm{X}$-ray sources, and electron field emission (EFE) flat-panel displays. The diamond nanostructures play a vital role for enhancing the EFE properties for practical applications. Previous studies have reported the better cathode properties of different diamond nanotips. ${ }^{10-17}$ On the other hand, the nitrogen vacancy $(\mathrm{NV})$ color center is a defect in diamond, which has been established as a proficient source for single photon emission at room temperature. ${ }^{18}$ The single photon source is a potential core for quantum key distribution and quantum computation. The enhancement in single photon emission has been reported from diamond nanowires, which is fabricated from single-crystalline diamond. ${ }^{18-20}$

\footnotetext{
Received: May 9, 2013

Accepted: July 12, 2013

Published: July 12, 2013
} 
Table 1. Growth Parameters of Different Morphological Diamond Films

$\begin{array}{llccc}\text { sample } & \text { gas composition }(\mathrm{sccm}) & \text { pressure }(\text { Torr }) & \text { microwave power }(\mathrm{W}) & \text { substrate temperature }\left({ }^{\circ} \mathrm{C}\right) \\ \mathrm{MCD} & \mathrm{CH}_{4} / \mathrm{H}_{2}(1 / 99) & 30 & 1600 & 550 \\ \mathrm{NCD} & \mathrm{CH}_{4} / \mathrm{H}_{2} / \mathrm{Ar}(1 / 50 / 49) & 70 & 1400 & 475 \\ \mathrm{UNCD} & \mathrm{CH}_{4} / \mathrm{Ar}(1 / 99) & 120 & 1200 & 20 \\ \mathrm{~N}-\mathrm{UNCD} & \mathrm{CH}_{4} / \mathrm{N}_{2}(6 / 94) & 50 & 1200 & 375\end{array}$

Diamond nanotips have been fabricated via the bottom-up approach on the template of porous anodic alumina. ${ }^{21}$ The simple and low-cost reactive ion etching (RIE) process has become the most promising technique for diamond nanostructuring, ${ }^{22-26}$ because the dimensions and geometries of nanostructures can be controlled by varying the power sources, gas composition, biasing voltage, and processing parameters for the plasma. Vertically aligned diamond nanowires fabricated from various diamond films with different lithography-defined patterns and masks via the RIE process has been investigated for numerous applications. ${ }^{27-33}$ The intrinsic impurities of diamond and self-forming mask $\left(\mathrm{Fe}_{2} \mathrm{O}_{3}\right)$ from the etching chamber are also found to play a role of mask for constructing the nanostructures. ${ }^{34,35}$ However, the etching mechanism for the diamond has not been clearly understood, because of the fact that the etching parameters required for the optimization of diamond nanostructures vary with the granular structure of the diamond films, in a complicated manner.

In this study, we investigated the significant role of diamond's granular structures in the fabrication of diamond nanostructures. The etching mechanism was explained by diagnosis of the reactive etching plasma using in situ optical emission spectroscopy (OES). The enhanced characteristics of nanostructures, especially those related to the potential applications as the electron field emitters and single photon sources, were demonstrated.

\section{EXPERIMENTAL SECTION}

The fabrication of diamond nanostructures were preceded by a threestep process. In the first step, four types of diamond films were grown on $\mathrm{Si}(100)$ substrates. Prior to the growth of diamond films, Si substrates were ultrasonically seeded with a mixture of diamond and titanium powders $(1: 1)$ in a methanol solution for $45 \mathrm{~min}$. The nucleated $\mathrm{Si}$ substrates were kept in a microwave plasma-enhanced chemical vapor deposition (MPE-CVD) system (2.45 GHz, IPLASCYRANNUS) for the growth of diamond films. The growth parameters of the diamond films are described in Table 1. Diamond films were named according to their morphology, grain size, and growth conditions: microcrystalline diamond (MCD) was used to describe the samples grown in $\mathrm{CH}_{4} / \mathrm{H}_{2}=1 / 99$ plasma, nanocrystalline diamond (NCD) was used to describe those grown in $\mathrm{CH}_{4} / \mathrm{H}_{2} / \mathrm{Ar}=$ $1 / 50 / 49$ plasma, ultrananocrystalline diamond (UNCD) was used to describe those grown in $\mathrm{CH}_{4} / \mathrm{Ar}=1 / 99$ plasma, and the term nitrogenincorporated UNCD (N-UNCD) described those grown in $\mathrm{CH}_{4} / \mathrm{N}_{2}=$ $6 / 94$ plasma. All these diamond films were grown to a thickness of $>1$ $\mu \mathrm{m}$.

In the second step, a thin gold film with a thickness of $4 \mathrm{~nm}$ was deposited on all of these diamond films via the DC sputtering process. The gold-coated diamond films were exposed to vacuum annealing (2 $\times 10^{-3}$ Torr) for $30 \mathrm{~min}$ at a temperature of $750{ }^{\circ} \mathrm{C}$ to form $\mathrm{Au}$ nanodots. No carbide with gold is expected, since the carbon solubility of gold is very low $\left(0.018\right.$ at. $\%$ at $800{ }^{\circ} \mathrm{C}$ in bulk phase). ${ }^{36,37}$ In the third step, self-assembled Au nanodots masked diamond samples were subjected to the self-biased RIE process with a reactive plasma of (95\%) $\mathrm{O}_{2}$ and $(5 \%) \mathrm{CF}_{4}$ gases. Gold was selected as a mask, because of the fact that the etching rate of the Au nanodots was markedly slower than the diamond for excited oxygen atom $\mathrm{O}^{*}$ and $\mathrm{F}$ reactive ions etching plasma. ${ }^{38}$ The etching plasma of the RIE process was sustained with a radio frequency $(\mathrm{rf})$ power of $150 \mathrm{~W}$, a process pressure of $150 \mathrm{mTorr}$, and the total gas flow rate of $25 \mathrm{sccm}$. [Note: $\mathrm{sccm}=$ standard cubic centimeters per minute.] The diamond films were systematically etched for periods of 10,20 , and $30 \mathrm{~min}$.

The constituent of reactive ions in the etching plasma were examined using OES. The surface morphology of pristine diamond films and RIE-etched diamond films were characterized by the fieldemission scanning electron microscopy (FESEM) (JEOL, Model $6500)$. The bonding structure of pristine diamond films and RIEetched diamond films were studied via UV-Raman spectroscopy $(\lambda=$ $325 \mathrm{~nm}$, Renishaw). The electronic structure of the pristine diamond films and nanostructures are examined by X-ray photoelectron spectroscopy (XPS; PHI 1600). The EFE characteristics of the RIEetched diamond samples were measured by a parallel-plate configuration, in which the diamond nanostructures were used as a cathode and a molybdenum rod with a diameter of $2 \mathrm{~mm}$ was used as an anode. Current-voltage $(I-V)$ characteristics were acquired using a Keithley Model 237 electrometer. The EFE characteristics of the diamond nanostructures were molded by means of Fowler-Nordheim (F-N) theory. ${ }^{39}$ The presence of NV center in diamond nanostructures was characterized by the photoluminescence (PL) with an excitation wavelength of $532 \mathrm{~nm}$ from Nd:YAG laser. PL measurement was performed on the diamond nanostructures, using a laser power of $100 \mu \mathrm{W}$, detector integration time of $1 \mathrm{~s}$, and measurement spot size of the laser is on the order of a micrometer (micro PL).

\section{RESULTS AND DISCUSSION}

3.1. The Effects of Diamond's Granular Structure on the Fabrication of Diamond Nanostructures. Figure 1a shows the FESEM image of pristine MCD film with faceted grains $\sim 400 \mathrm{~nm}$ in size, whereas the inset of this figure shows that the MCD film has a columnar structure. ${ }^{40}$ Figure $1 \mathrm{~b}$ shows the FESEM image of pristine NCD film, which has the cauliflower-like diamond aggregates $\sim 50 \mathrm{~nm}$ in size. ${ }^{40}$ Similar to that observed with MCD film growth, the NCD film has also grown by means of a columnar structure but contains subcolumns on the order of $10 \mathrm{~nm}$ in size (see inset of Figure $1 b)$, which is the same size as the grain size in this film. ${ }^{23}$ The columns of NCD film contain nanosized diamond grains with grain boundaries rich in graphite and amorphous carbon (a-C).

Figure 1c shows the FESEM image of pristine UNCD film. The transmission electron microscopy (TEM) micrograph in the inset of Figure 1c indicates that UNCD films consist of ultrasmall diamond grains with spherical geometry and grains $\sim 5 \mathrm{~nm}$ in size. ${ }^{40}$ By reducing the grain sizes of diamond film, there is an increase in the number of grain boundaries. ${ }^{41}$ The grain boundaries contain the nondiamond carbon such as a-C or trans-polyacetylene phase. ${ }^{42}$ Figure $1 \mathrm{~d}$ shows the FESEM image of the pristine N-UNCD film. The inset in Figure 1d shows the TEM micrograph, revealing that the N-UNCD film contains needlelike grains $<5 \mathrm{~nm}$ in diameter and hundreds of nanometers in length. Each needlelike grain is encased in a graphitic shell approximately a few nanometers thick, resulting in a huge amount of graphitic grain boundaries. ${ }^{43}$ The different granular structures for MCD, NCD, UNCD, and N-UNCD films play a key role for the formation of nanostructures using RIE, which will be discussed shortly. 


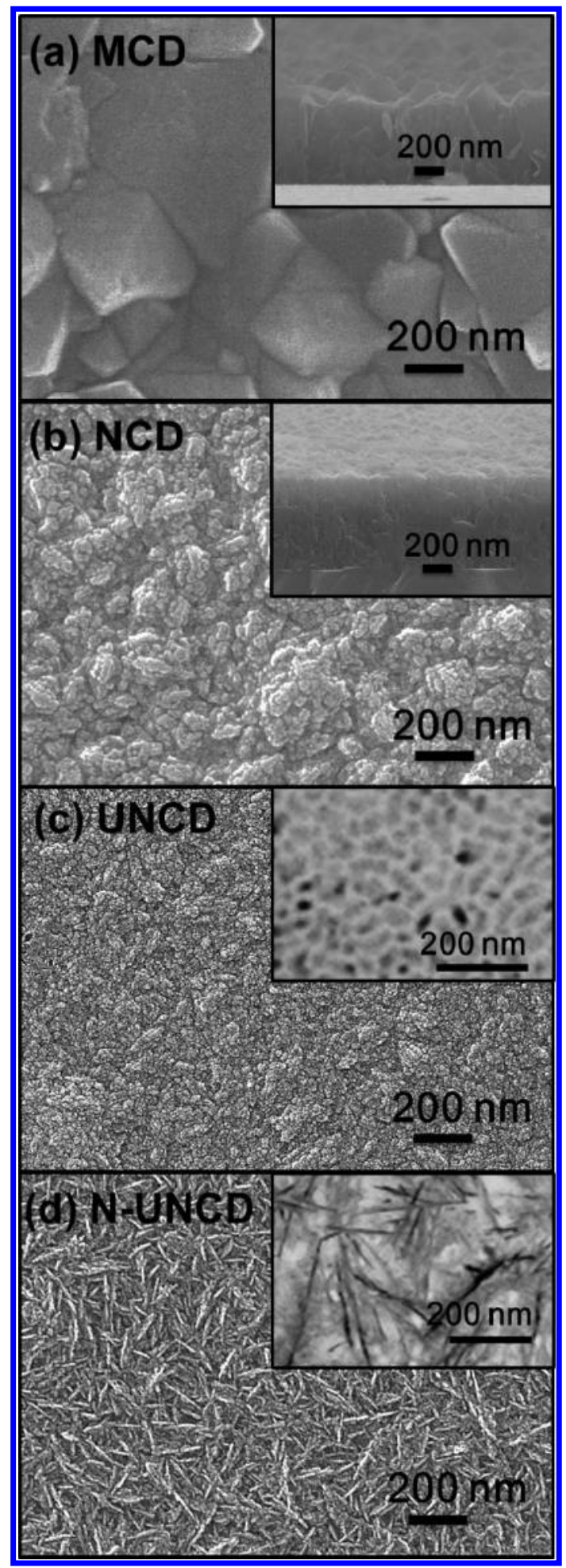

Figure 1. Field-emission scanning electron microscopy (FESEM) micrograph of pristine (a) MCD film, (b) NCD film, (c) UNCD film, and (d) N-UNCD film.

Figure 2a shows nonuniformly distributed gold clusters of irregular shape formed by dewetting the gold thin film on MCD grains that could play the role of a mask. The etching of MCD was initiated from defective carbon, which is the $\mathrm{sp}^{2}$-bonded carbons transformed from the $\mathrm{sp}^{3}$-bonded carbons in diamond by means of ion bombardment, viz, the energetic $\mathrm{O}$ and $\mathrm{F}$ ions, which were accelerated toward the diamond substrate via rf-

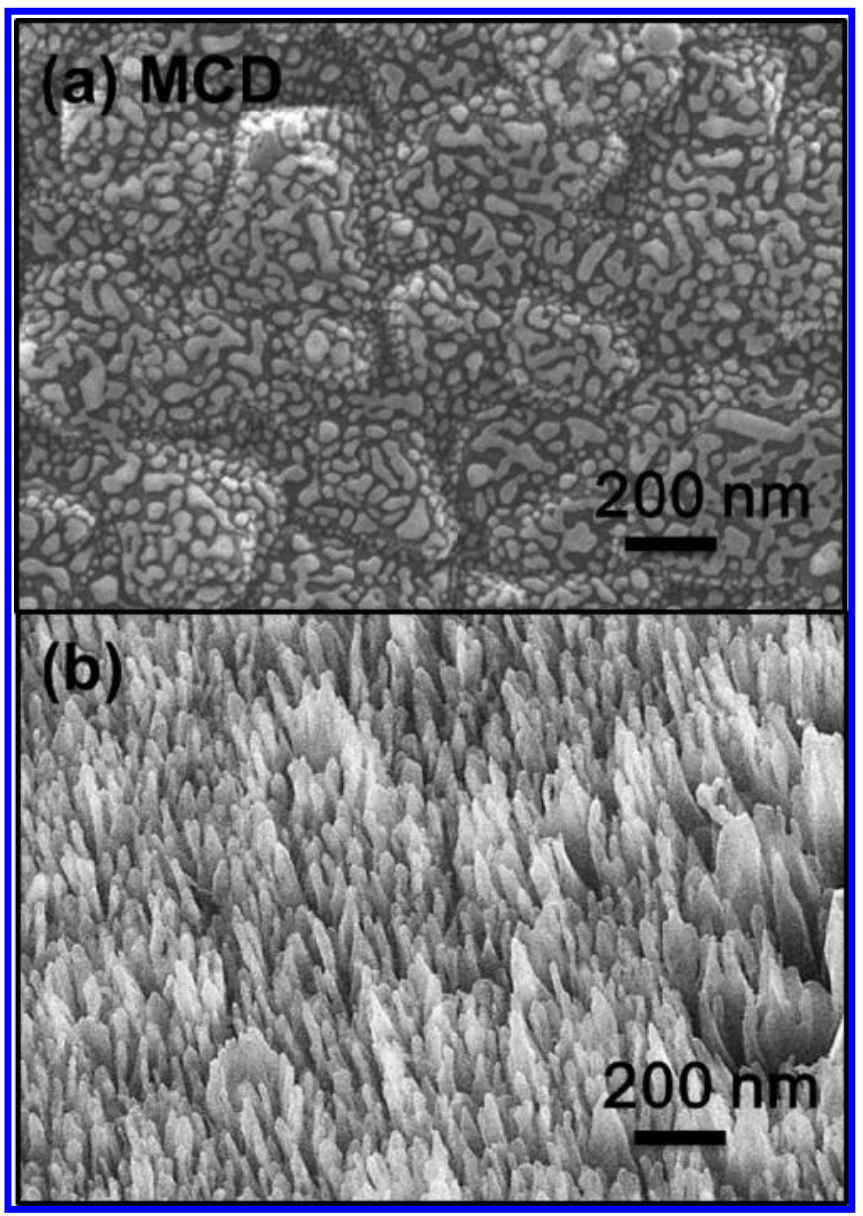

Figure 2. FESEM micrographs of (a) the Au nanodots and (b) the nanocones obtained after $30 \mathrm{~min}$ of reaction-ion etching (RIE) of the MCD film.

bias, preferentially etched the defective carbons. ${ }^{33}$ Figure $2 b$ illustrates the vertically aligned highly dense MCD nanocones with different sizes attained after $30 \mathrm{~min}$ of RIE etching, whereas those for the etching times of 10 and 20 min are shown as Figures $\mathrm{S} 1(\mathrm{a})$ and $\mathrm{S} 1(\mathrm{~b})$ in the Supporting Information. Here, each MCD grain has renewed into numerous nanocones. The number of nanocones is dependent on the density of $\mathrm{Au}$ nanodots, which are formed on each grain.

Figures $3 \mathrm{a}$ and $4 \mathrm{a}$ show the uniformly distributed, highly dense Au nanodots $(\sim 40 \mathrm{~nm})$ with spherical geometry formed by dewetting the gold thin film on NCD and UNCD film surface, respectively. The size of Au nanodots on NCD film is similar to the size of the NCD grains. As a result, each individual grain of NCD is covered by $\mathrm{Au}$ nanodots, which performs as a mask in the etching process. The well-aligned, high-density NCD diamond nanotips are formed after $30 \mathrm{~min}$ of etching, as shown in Figure $3 b$, which imply that each columnar grain is shaped into a single nanotip. The initiation of etching for vertically aligned highly dense NCD nanotips and the role of Au mask observed for the etching times of 10 and 20 min (see Figures S2(a) and S2(b) in the Supporting Information). In contrast, the well-shaped, uniformly aligned, highly dense UNCD nanopillars $40 \mathrm{~nm}$ in size are obtained from UNCD films after 30 min of RIE etching (see Figure 4b). The SEM of 10- and 20-min-etched samples are show as Figures S3(a) and S3(b) in the Supporting Information. The 


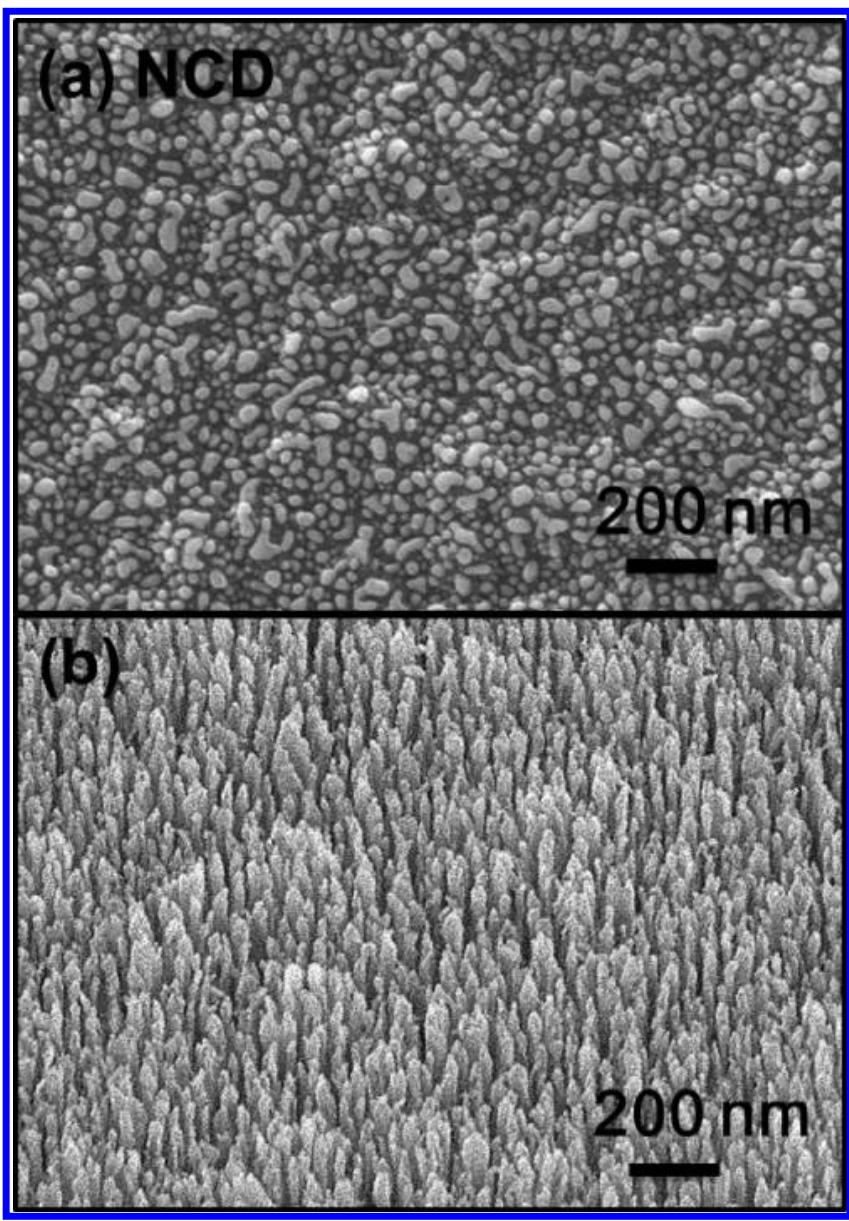

Figure 3. FESEM micrograph of (a) the Au nanodots and (b) the nanotips obtained after 30 min RIE etching of the NCD film.

uniformity, density, and shape of nanopillars are dependent on gold clusters formed on UNCD films.

In contrast, Figure 5a shows uniform distribution of $\mathrm{Au}$ nanodots $20 \mathrm{~nm}$ in size, because of dewetting of the gold thin film on the N-UNCD surface. The shape of the Au nanodots is totally different from those of other diamond films. Smallersized spherical nanodots are formed on the surface of $\mathrm{N}$ UNCD needlelike grains. Figure $5 b$ shows highly dense NUNCD nanograss structures obtained after $30 \mathrm{~min}$ of the RIE etching process. The N-UNCD nanostructures of 10- and 20min-etched samples are shown in Figures S4(a) and S4(b) in the Supporting Information. The rates of etching for the MCD, NCD, UNCD, and N-UNCD films are observed to have values of $15,20,30$, and $32 \mathrm{~nm} / \mathrm{min}$, respectively (see Table 1).

3.2. Surface Analysis of Diamond Nanostructures. Figures $6 a-d$ describe the UV-Raman spectra of the pristine and 30-min RIE-etched diamond films. Generally, the largegrain diamond films, MCD and NCD films, contain a sharp peak at the Raman shift of $1332 \mathrm{~cm}^{-1}$ (D-band), representing the $\mathrm{F}_{2 \mathrm{~g}}$-band of diamond carbon, and broad peak at Raman shift of $1572 \mathrm{~cm}^{-1}$ (G-band), ${ }^{44}$ representing the presence of graphitic carbon (curve I in Figures $6 \mathrm{a}$ and $6 \mathrm{~b}$ ). In contrast, the ultrasmall granular structured diamond films, UNCD and N-UNCD, consist of a broaden peak observed at Raman resonance of $1333 \mathrm{~cm}^{-1}$ (D-band), representing the first-order Raman peak, and at a Raman resonance of $1585 \mathrm{~cm}^{-1}$ (Gband), representing the graphitic carbon for UNCD and NUNCD (curve I in Figures $6 \mathrm{c}$ and $6 \mathrm{~d}$ ). The extra Raman peak

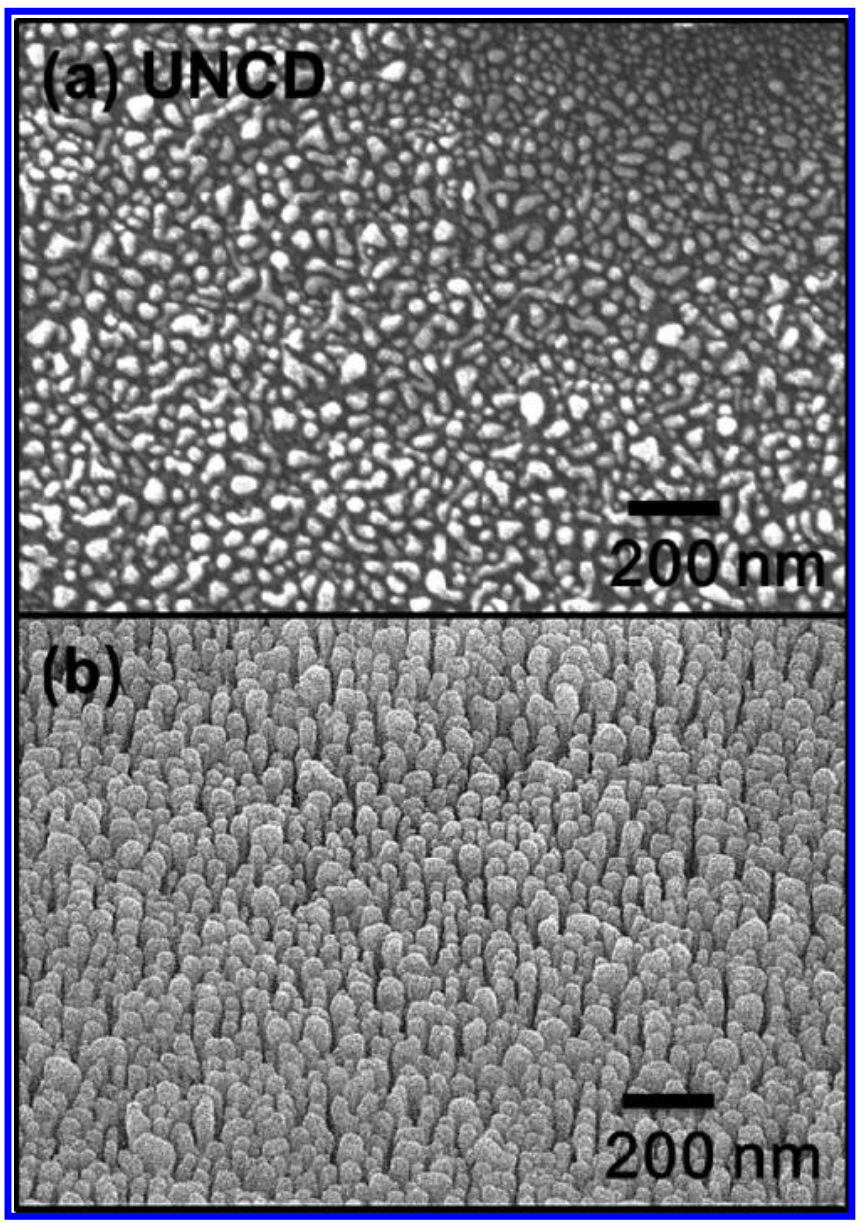

Figure 4. FESEM micrograph of (a) the Au nanodots and (b) the nanopillars obtained after 30 min RIE etching of the UNCD film.

appeared at $1405 \mathrm{~cm}^{-1}$ ( $\mathrm{D}^{*}$-band) for N-UNCD, representing the disordered carbon. ${ }^{45}$ The intensities of the peaks are reduced after RIE etching of $30 \mathrm{~min}$ (see curve II in Figures $6 \mathrm{a}-\mathrm{d})$.

No Raman peak shift is observed for the D-band, which reveals that the RIE process does not alter the crystallinity of diamond, ${ }^{27}$ regardless of the granular structure of the diamond film. In contrast, there is slight blue shift of the G-band, which shows the conversion of crystalline $\mathrm{sp}^{2}$ bonds into a-C ones (or vice versa). The ratio of intensities of the $\mathrm{D}$-peak to the G-peak $\left(I_{\mathrm{D}} / I_{\mathrm{G}}\right)$ is large $(\sim 2.054)$ for large-grained diamond films (MCD) and is small $(\sim 0.435)$ for fine-grained diamond films (NCD), implying again that the NCD film contains a large proportion of grain boundaries, relative to that of MCD film. In contrast, for ultrasmall granular structured UNCD and NUNCD films, the $I_{\mathrm{D}} / I_{\mathrm{G}}$ ratio is small $(\sim 0.420)$ for UNCD film and is large for N-UNCD film $(\sim 0.57)$, which is probably due to high surface to volume ratio of spherical-shaped UNCD grains, compared to that of N-UNCD needlelike grains. Moreover, the $I_{\mathrm{D}} / I_{\mathrm{G}}$ ratio increases slightly for all diamond films after a 30-min RIE etching process, i.e., the $I_{\mathrm{D}} / I_{\mathrm{G}}$ ratio increases from 2.054 to 2.780 for MCD film, 0.431 to 0.694 for NCD film, 0.42 to 0.435 for UNCD film, and 0.527 to 0.57 for N-UNCD film. In addition, a blue shift in the G-band and increases in $I_{\mathrm{D}} / I_{\mathrm{G}}$ ratios were keenly observed, indicating that non-diamond phase formation due to damage occurred via ion bombardment of the RIE process. ${ }^{46-48}$ 


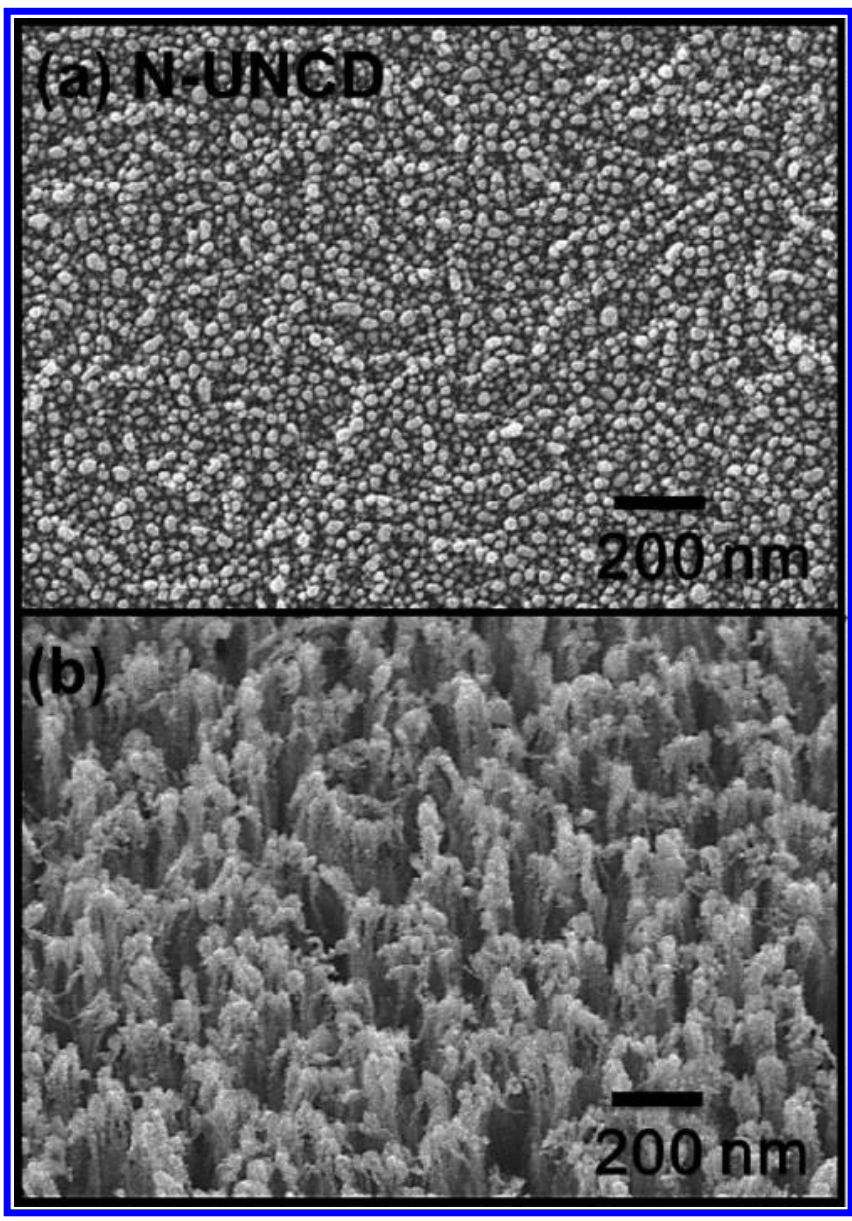

Figure 5. FESEM micrograph of (a) the Au nanodots and (b) the nanograss structures obtained after $30 \mathrm{~min}$ of RIE etching of the $\mathrm{N}$ UNCD film.

Generally, RIE damaged the surface of diamond films by means of high-energy ion bombardment throughout the process $^{34,49}$ that was examined by XPS measurements on the pristine diamond films and diamond nanostructures. $\mathrm{C} 1 \mathrm{~s}$ peak has been adopted magnificently to estimate the $\mathrm{sp}^{3}$ content in diamond films and nanostructures. XPS spectra of diamond films and nanostructures have been obtained by using the $\mathrm{Al}$ $\mathrm{K} \alpha$-line. The measurements were conducted without ion sputtering etching, to avoid reconfiguration of the bonds. Figure 7 describes the XPS results of the diamond films and nanostructures. The typical C 1s core level line of all the films and nanostructures was fitted by using the Lorentzian peaks at their corresponding binding energies of $\mathrm{sp}^{2} \mathrm{C}=\mathrm{C}(\sim 285.1 \mathrm{eV})$, $\mathrm{sp}^{3} \mathrm{C}-\mathrm{C}(\sim 286.2 \mathrm{eV}), \mathrm{sp}^{3} \mathrm{C}-\mathrm{N}(\sim 285.8 \mathrm{eV}), \mathrm{sp}^{2} \mathrm{C}=\mathrm{N}$ $(\sim 286.1 \mathrm{eV})$, and $\mathrm{sp}^{3} \mathrm{C}-\mathrm{O}-\mathrm{C}(\sim 286.5 \mathrm{eV}) .^{50,51}$ The background was detracted using Shirley's method. The detailed ratios of $\mathrm{sp}^{3}$-carbon and $\mathrm{sp}^{2}$-carbon of pristine diamond films and their nanostructures has been shown in Table 2. Figures $7 \mathrm{a}$ and $7 \mathrm{~b}$ show the X-ray photoelectron spectroscopy (XPS) of pristine MCD films and nanocones. It has been observed that, while the $\mathrm{sp}^{3} \mathrm{C}-\mathrm{C}$ peak of pristine diamond films and nanocones were observed at 285.4 and $286.57 \mathrm{eV}$, respectively, and the peak intensity reduced from $46.1 \%$ to $37 \%$ as a result of $\mathrm{RIE}$ etching, the $\mathrm{sp}^{2} \mathrm{C}=\mathrm{C}$ peak shifts from $284.8 \mathrm{eV}$ to 285.07 and the amount of $\mathrm{sp}^{2}$ carbon increases from $40.4 \%$ to $48.8 \%$ after RIE etching. The $\mathrm{sp}^{2} / \mathrm{sp}^{3}$ ratio increases from 0.88 to 1.37 , because of RIE etching. The $\mathrm{sp}^{3} \mathrm{C}-\mathrm{N}$ and $\mathrm{C}-\mathrm{O}-\mathrm{C}$ peaks were

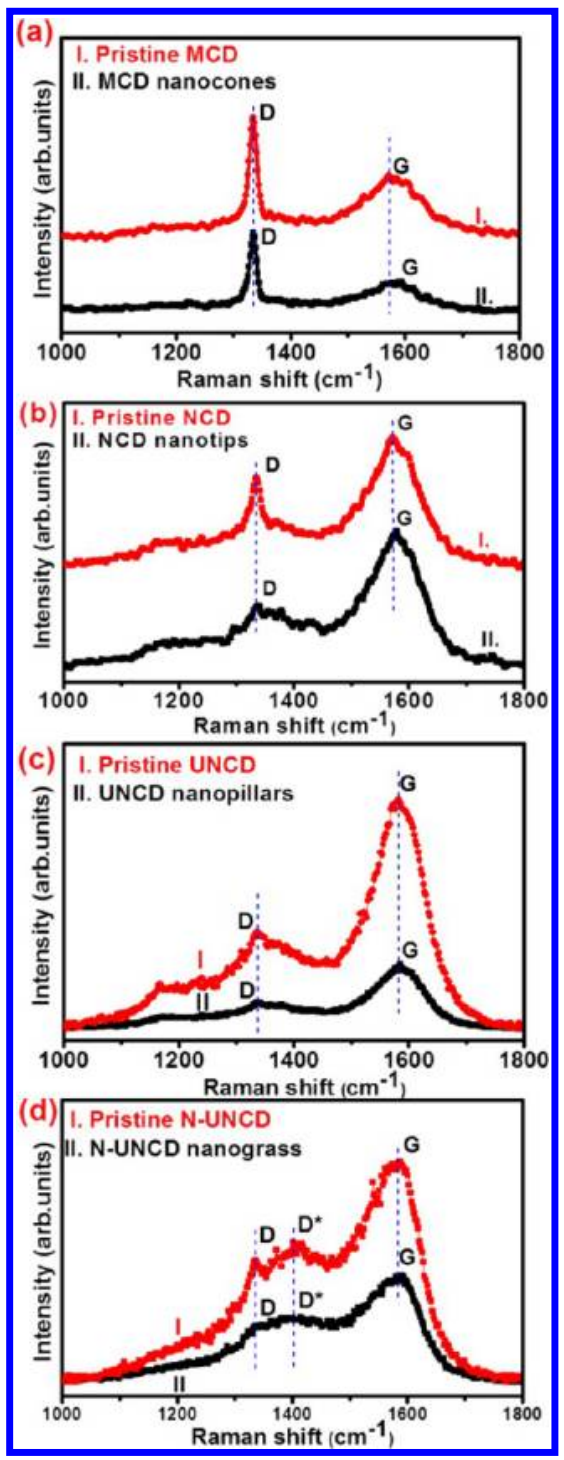

Figure 6. UV-Raman spectra for (a) MCD, (b) NCD, (c) UNCD, and (d) N-UNCD, where curve I represents pristine diamond film and curve II represents the 30-min RIE-etched nanostructures.

identified at 285.8 and $286.5 \mathrm{eV}$, respectively, for both samples. The peak intensities of $\mathrm{C}-\mathrm{N}$ and $\mathrm{C}-\mathrm{O}-\mathrm{C}$ remained essentially the same value of $10.2 \%$ and $3.2 \%-3.6 \%$, respectively. Figures $7 \mathrm{c}$ and $7 \mathrm{~d}$ illustrate the XPS results of pristine NCD films and nanotips. These figures show the similarly trend, viz. the $\mathrm{sp}^{3}$ $\mathrm{C}-\mathrm{C}$ peak decrease and the $\mathrm{sp}^{2} \mathrm{C}=\mathrm{C}$ peak increases, whereas the $\mathrm{sp}^{3} \mathrm{C}-\mathrm{N}$ and $\mathrm{C}-\mathrm{O}-\mathrm{C}$ peaks remain essentially the same, due to RIE etching. The NCD films contain slightly larger proportion of $\mathrm{sp}^{2} / \mathrm{sp}^{3}$ ratio than the MCD films and the $\mathrm{sp}^{2} / \mathrm{sp}^{3}$ ratio increases from 0.97 to 1.43 after RIE etching.

Figures $7 \mathrm{e}$ and $7 \mathrm{f}$ depict the XPS of pristine UNCD films and nanopillars, respectively, whereas Figures $7 \mathrm{~g}$ and $7 \mathrm{~h}$ show the XPS of pristine N-UNCD films and nanograss, respectively. These figures (and Table 2) show that the $\mathrm{sp}^{2} \mathrm{C}=\mathrm{C}$ peak (48\%) and the $\mathrm{sp}^{2} / \mathrm{sp}^{3}$ ratio (1.24) for UNCD films is markedly larger than those for MCD (or NCD) films. The $\mathrm{sp}^{2} / \mathrm{sp}^{3}$ ratio increases from 1.24 for pristine UNCD films to 1.34 for UNCD nanopillars. The percentage of $\mathrm{sp}^{2} \mathrm{C}=\mathrm{C}$ peak $(25.7 \%)$ in $\mathrm{N}$ UNCD films is smaller than other pristine diamond films that is due to the presence of a large amount of $\mathrm{sp}^{2} \mathrm{C}=\mathrm{N}$ bonds contained in these films. Nevertheless, the $\mathrm{sp}^{2} / \mathrm{sp}^{3}$ ratio for $\mathrm{N}$ - 


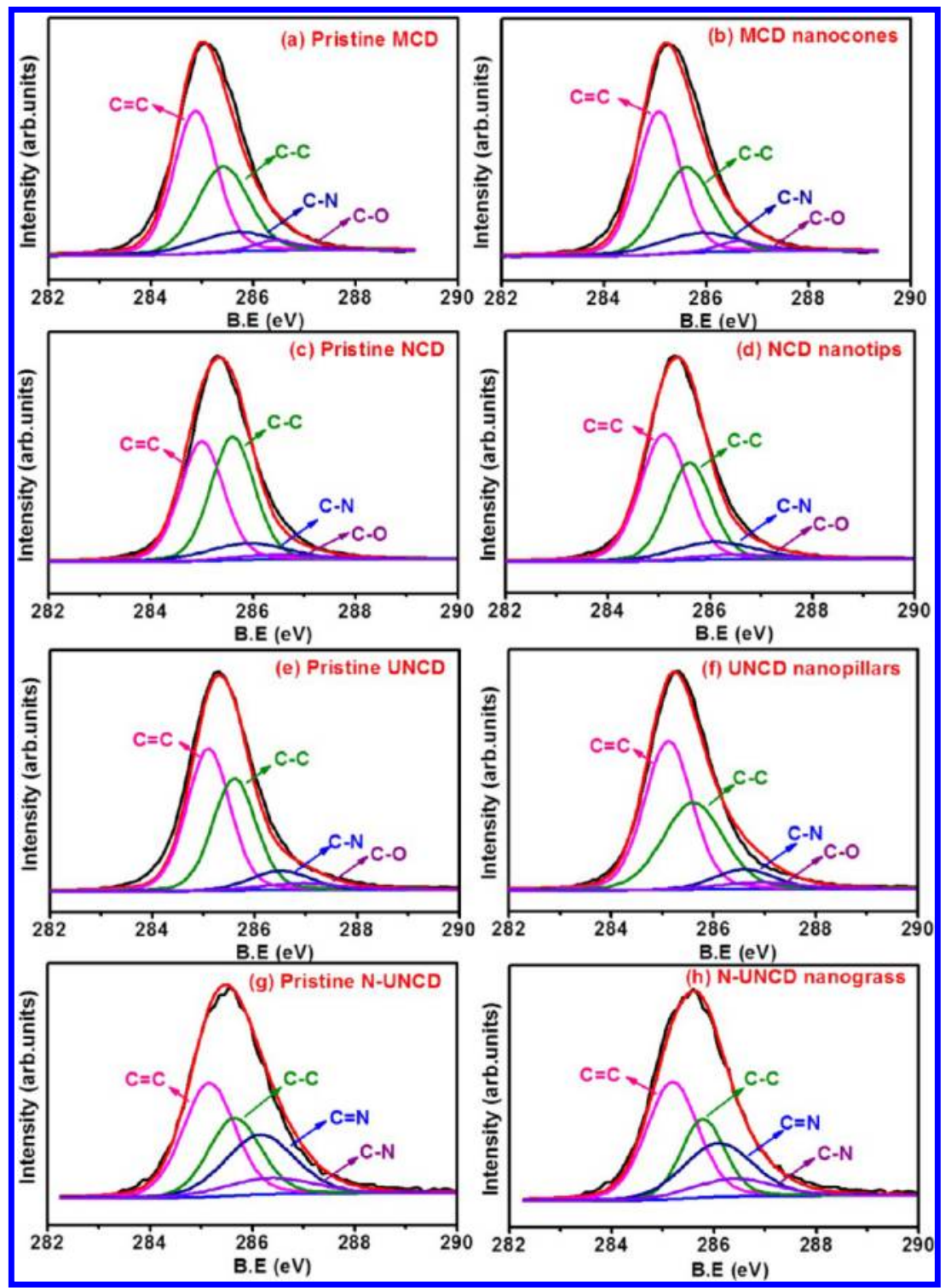

Figure 7. X-ray photoelectron spectroscopy (XPS) of (a) pristine MCD, (b) MCD nanocones, (c) pristine NCD, (d) NCD nanotips, (e) pristine UNCD, (f) UNCD nanopillars, (g) pristine N-UNCD films, and (h) N-UNCD-nanograss.

Table 2. Relative Intensities of Various Components of C 1s XPS Spectra from Diamond Films and Nanostructures

\begin{tabular}{|c|c|c|c|c|c|c|c|c|}
\hline \multirow[b]{3}{*}{ chemical bonding } & \multicolumn{8}{|c|}{ Relative Peak Intensity (\%) } \\
\hline & \multicolumn{2}{|c|}{$\mathrm{MCD}$} & \multicolumn{2}{|c|}{ NCD } & \multicolumn{2}{|c|}{ UNCD } & \multicolumn{2}{|c|}{ NUNCD } \\
\hline & film & nanocone & film & nanotip & film & nanopillar & film & nanograss \\
\hline $\mathrm{sp}^{3} \mathrm{C}-\mathrm{C}(285.0 \mathrm{eV})$ & 46.1 & 37.0 & 43.5 & 35.7 & 38.7 & 36.9 & 25.7 & 23.2 \\
\hline $\mathrm{sp}^{2} \mathrm{C}=\mathrm{C}(285.5 \mathrm{eV})$ & 40.4 & 48.9 & 42.2 & 49.8 & 48.4 & 50.1 & 38.7 & 41.3 \\
\hline $\mathrm{sp}^{3} \mathrm{C}-\mathrm{N}(285.8 \mathrm{eV})$ & 10.2 & 10.2 & 11.1 & 11.1 & 8.6 & 8.6 & 9.3 & 9.25 \\
\hline $\mathrm{sp}^{2} \mathrm{C}=\mathrm{N}(286.1 \mathrm{eV})$ & 0 & 0 & 0 & 0 & 0 & 0 & 26.0 & 25.6 \\
\hline $\mathrm{sp}^{3} \mathrm{C}-\mathrm{O}-\mathrm{C}(286.5 \mathrm{eV})$ & 3.2 & 3.9 & 3.1 & 3.2 & 4.2 & 4.4 & 0 & 0 \\
\hline $\mathrm{sp}^{2} / \mathrm{sp}^{3}$ ratio & 0.88 & 1.37 & 0.97 & 1.43 & 1.24 & 1.34 & 1.51 & 1.78 \\
\hline
\end{tabular}

UNCD films is largest (1.51) among the pristine diamond films and increases to 1.78 after RIE etching.

Restated, the XPS results of pristine diamond films reveal that the relative amount of $\mathrm{sp}^{2} \mathrm{C}=\mathrm{C}$ carbon and the $\mathrm{sp}^{2} / \mathrm{sp}^{3}$ ratio increase as the granular structure changed from $\mathrm{MCD}$, $\mathrm{NCD}$, and UNCD, to N-UNCD films, whereas those of the diamond nanostructures illustrated an increase of $\mathrm{sp}^{2} \mathrm{C}=\mathrm{C}$ carbon and the $\mathrm{sp}^{2} / \mathrm{sp}^{3}$ ratio due to ion bombardment during the RIE process. Moreover, from the close relationship between the etching rates and the relative $\mathrm{sp}^{2}$ content of the pristine diamond films, we can state that rate of etching increases as the intrinsic graphic content of the pristine diamond films increases. From the phenomenon that the $\mathrm{sp}^{2}$ content increase as the pristine diamond films were converted to diamond nanostructure, we can say that O-species bombardment in RIE 
process has converted the $\mathrm{sp}^{3}$-bonded carbons into $\mathrm{sp}^{2}$-bonded ones that is in accord with the proposed etching mechanism.

3.3. The Characterization of Etching Plasma and the Etching Mechanism. The morphology of the RIE-induced diamond nanostructures is closely related to the size and distribution of $\mathrm{Au}$ nanodots formed on the diamond films, as well as to the granular structure of the pristine diamond films. The Au films were dewetted and coalescenced freely on MCD and UNCD films, forming Au nanodots with irregular geometry and nonuniform distribution (cf. Figures 2a and 4a). With regard to the NCD film, the grain boundaries form a nature boundary when the dewetted $\mathrm{Au}$ film coalescences to form $\mathrm{Au}$ nanodots, such that the Au nanodots are sitting on the NCD grains and the sizes of $\mathrm{Au}$ nanodots are approximately the same as that of the NCD grains (cf. Figure 3a). The Au nanodots are more uniform in size distribution. Same phenomenon occurs for N-UNCD films. In this case, the needlelike grains, $\sim 5 \mathrm{~nm}$ in diameter and hundreds of nanometers in length, are separated by wide grain boundaries, which act as nature boundaries for the coalescence of the Au layer. Small-sized needlelike grains resulted in markedly smaller-sized spherical-shaped Au nanodots (cf. Figure 5a). The nonmasked regions of all the morphologies, particularly the grain boundaries, which contain a larger proportion of $\mathrm{sp}^{2}$-bonded carbon, will be etched out initially by the reactive ions; as a result of this phenomenon, etching paths will be initiated.

To understand the etching mechanism, we examined the characteristics of the etching plasma using OES. Figure 8 shows

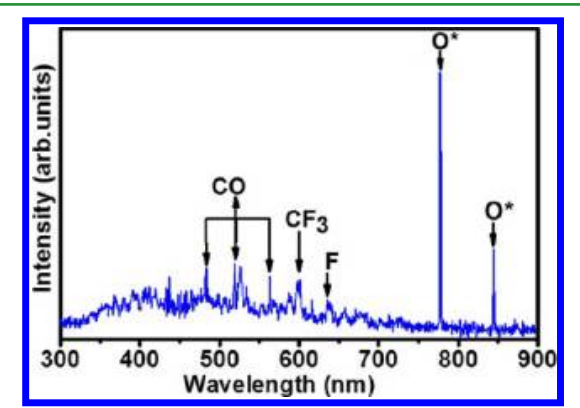

Figure 8. Optical emission spectrum of oxygen $(95 \%)+\mathrm{CF}_{4}(5 \%)$ etching plasma used in the RIE process.

the OES of $\mathrm{O}_{2}+\mathrm{CF}_{4}$ plasma used to etch the diamond in selfbiased RIE process. The prominent peaks observed at wavelengths of 777.4 and $844.6 \mathrm{~nm}$ are the emission peaks of excited oxygen atoms $\left(\mathrm{O}^{*}\right)^{52}$ and other intense emissions of carbon monoxide are detected at wavelengths of 483.0, 519.5, and $561.0 \mathrm{~nm} .{ }^{53}$ The excited atomic oxygen $\left(\mathrm{O}^{*}\right)$ is formed via dissociative excitation of $\mathrm{O}_{2}$ and direct excitation of $\mathrm{O}$ by the electron collision, ${ }^{54}$ which are described in eqs 1 and 2 :

$$
\begin{aligned}
& e+\mathrm{O}_{2} \rightarrow \mathrm{O}+\mathrm{O}^{*}+e \rightarrow 2 \mathrm{O}+e+h \nu \\
& e+\mathrm{O} \rightarrow \mathrm{O}^{*}+e+h \nu
\end{aligned}
$$

The most prominent $\mathrm{O}^{*}$ atoms in the rf plasma cause the diamond etching and the less-intense $\mathrm{CO}$ species remove the carbon by forming volatile products from the etching plasma. The diamond etching process is occurring via a two-step process. ${ }^{28}$ The initial step is the physical etching (sputtering) by bombardment of the high-energy $\mathrm{O}^{*}$ species on the diamond. In the second step, sputter-etched carbon species are chemically bonded with active $\mathrm{O}^{*}$ atoms, forming volatile $\mathrm{CO}$ gas molecules. In addition, the ion bombardment also induces graphitization on diamond's topmost layer that transforms the $\mathrm{sp}^{3}$-bonded diamond carbons into $\mathrm{sp}^{2}$-bonded ones. The subsequent incident $\mathrm{O}^{*}$ atoms bombardment may also chemically etch the damaged diamond surface by reacting with the $\mathrm{sp}^{2}$-bonded carbon preferentially, while the $\mathrm{sp}^{3}$-bonded carbon in diamond remains intact. The main advantage of $\mathrm{CF}_{4}$ addition in the etching plasma is to reduce the surface roughness of the etched diamond. ${ }^{55,56}$ The discharge of $\mathrm{CF}_{4}$ molecule by electron impact can generate the $\mathrm{CF}_{3}^{-}, \mathrm{CF}_{3}, \mathrm{CF}_{2}$, $\mathrm{F}^{-}$, and $\mathrm{F}$ ions in the reactive plasma of RIE, ${ }^{57}$ which have been observed at wavelengths of $599.0 \mathrm{~nm}$ for $\mathrm{CF}_{3}$ and $637.0 \mathrm{~nm}$ for the $\mathrm{F}$ ion, respectively.

The etching of polycrystalline MCD film is essentially the same as that of single-crystalline diamond. For the MCD film, the anisotropic etching process initiated by the conversion of $\mathrm{sp}^{3}$-bonded carbon to $\mathrm{sp}^{2}$ is due to ion bombardment. Once the etching started around the $\mathrm{Au}$ dot, the ion bombardment occurred vertically, which causes efficient etching and creates initial etching paths. As the etching time was increased, the boundaries of the Au dot also were etched out by ions. These new etching paths caused the architecture to assume a conelike shape (cf. Figure $2 \mathrm{~b}$ ). The sample with an etching time of 10 min shows small cones with $\mathrm{Au}$ nanodots on the top and a decrease in $\mathrm{Au}$ nanodot size (see Figure S1(a) in the Supporting Information). The each individual grain of MCD is fabricated into number of cone-shaped nanostructures. The size of the $\mathrm{Au}$ nanodots shrinks gradually with increasing etching time and the etching initiated around the cone shape becomes larger. ${ }^{50}$ Such an etching mechanism is supported by the observation of the 20-min-etched sample, which shows sharp cones with small Au nanodots on top (see Figure S1(a) in the Supporting Information).

In contrast, for the NCD film, the well-aligned, highly dense diamond nanotips are formed because of $30 \mathrm{~min}$ of RIE etching (cf. Figure $3 b$ ). The NCD film contains nanodiamond grains separated by the grain boundaries, and, primarily, the $\mathrm{Au}$ nanodots are on the top of each subcolumn. The grain boundaries contain a large proportion of $\mathrm{sp}^{2}$-carbon and a-C phases. Initially, the etching of NCD films starts from the boundaries of $\mathrm{Au}$ nanodots, and significant etching will take place around the subcolumn and shaped in to a single nanotip. Because of the ease of etching the $\mathrm{sp}^{2}$-bonded and $\mathrm{a}-\mathrm{C}$ from the boundaries of NCD columnar grains, an etching path for shaping the nanotips is created. ${ }^{23}$ The formation of nanotips starts after 20 min of etching, because of the gradual decrease in the Au mask coverage with anisotropic etching, which results in sharp nanotips $\sim 40 \mathrm{~nm}$ in size at the bottom and $10 \mathrm{~nm}$ in size at the top of the nanotips (see Figures S2(a) and S2(b) in the Supporting Information).

The etching process of the UNCD film is almost similar to that of the NCD film, but the difference stems from its ultrasmall granular structure, which creates a nanopillar-like structure (cf. Figure 4b). The UNCD film contains grains $5 \mathrm{~nm}$ in size and a large number of $\mathrm{sp}^{2}$-bonded carbon in grain boundaries, compared to MCD and NCD films. The UNCD nanopillars are constructed by a total etching of the ultrananosized grains from the etching paths, which are the boundaries surrounding the $\mathrm{Au}$ nanodots. The UNCD nanopillars $40 \mathrm{~nm}$ in size are thus obtained after $30 \mathrm{~min}$ of RIE etching (cf. Figure $4 \mathrm{~b}$ ). In the case of N-UNCD etching, we follow the same etching conditions and masking process. But we obtain highly dense nanograss structures, which are due to the needlelike granular structure of the N-UNCD film. The 
N-UNCD grains have grown like tiny nanoneedles arbitrarily blown in random directions. The graphite phases surrounding the needlelike grains are etched out preferentially, allowing the diamond needles to remain intact. The needlelike grains are stacked along the columns underneath the randomly oriented $\mathrm{Au}$ nanodots mask, resulting in the formation of nanograss structures. Because of the high content of nondiamond carbon phases, the rate of etching for UNCD and N-UNCD film is higher than the MCD and NCD films (cf. Table 1).

3.4. The EFE and PL Properties of Diamond Nanostructures: Potential Applications. One of the aspects of concern in the RIE process is the redisposition of etched mask materials (Au). The FESEM-energy dispersive spectroscopy (FESEM-EDS) profile is collected from the 30min-etched samples and the typical EDS profile is shown as Figure S5 in the Supporting Information. The EDS profile confirms the presence of a high carbon content and a small amount of $\mathrm{Si}$ from diamond nanostructures. No $\mathrm{Au}$ mask materials exist after $30 \mathrm{~min}$ of etching in the RIE process.

The electron field emitters have great potential in the development of vacuum electronic devices. The EFE process is an electron tunneling phenomenon from the cathode surface to vacuum by applying the bias voltage on the cathode that can be modeled by the $\mathrm{F}-\mathrm{N}$ relation. ${ }^{39}$ Here, we illustrate the EFE properties of different diamond nanostructures developed using the RIE process (Figure 9) with the insets showing the

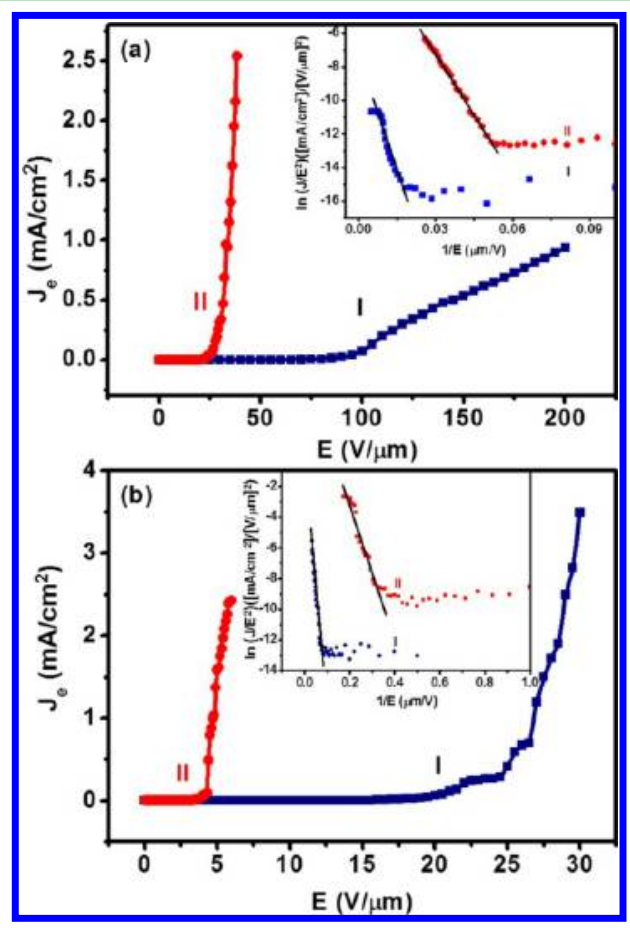

Figure 9. Electron field emission (EFE) properties of 30-min RIEetched nanostructures: (a) MCD nanocones (curve I) and NCD nanotips (curve II); (b) UNCD nanopillars (curve I) and N-UNCD nanograss structures (curve II).

corresponding $\mathrm{F}-\mathrm{N}$ plots. The measurements were carried out for the 30-min RIE-etched diamond nanostructures, because of the high aspect ratio. Figure 9a shows that, for MCD nanocones (curve I), the turn-on field $\left(E_{0}\right)$ of $35.0 \mathrm{~V} / \mu \mathrm{m}$ is required to induce the field emission, and the electron current density value of $J_{\mathrm{e}}=0.91 \mathrm{~mA} / \mathrm{cm}^{2}$ is obtained at an applied field of $200 \mathrm{~V} / \mu \mathrm{m}$. The field enhancement factor $(\beta)$ is estimated from the slope of the $\mathrm{F}-\mathrm{N}$ plots in the high-field region and MCD nanocones possess the $\beta$ value of 259 . Moreover, the NCD nanotips possess markedly better EFE properties, compared to MCD nanocones (curve II, Figure 9a). The NCD nanotips achieve an $E_{0}$ value of $16.2 \mathrm{~V} / \mu \mathrm{m}$; with a $J_{\mathrm{e}}$ value of $2.5 \mathrm{~mA} / \mathrm{cm}^{2}$, an applied field of $38 \mathrm{~V} / \mu \mathrm{m}(\beta=347)$ is achieved. The values of $E_{0}$ and $J_{\mathrm{e}}$ of NCD nanostructures are superior to MCD nanostructures that are due to the high fraction of $\mathrm{sp}^{2}$-bonded carbon, encasing the diamond nanostructures, which operate as electron-conducting channels. In the case of NCD nanotips, the $J_{\mathrm{e}}$ value is improved by a factor of 10 , relative to that of MCD nanocones.

However, the electron transport efficiency for NCD nanotips is still limited, because the NCD nanotip consists of NCD columnar diamond grains $20 \mathrm{~nm}$ in size. The size of the columnar grains is similar to the size of nanotips that are not sufficiently conductive. In contrast, UNCD (or N-UNCD) nanostructures consist of ultrasmall diamond grains $(\sim 5 \mathrm{~nm})$, which are much smaller than the size of the MCD or NCD nanostructures. The UNCD (or N-UNCD) nanostructures contain a graphitic phase (or trans-polyacetylene phase), located between the diamond grains, viz, the UNCD (or NUNCD) nanostructures are actually hybrid materials, containing nanosized diamond grains embedded in the matrix of graphite (or a-C), which are highly conducting. Figure 9b shows that the EFE properties are markedly enhanced for UNCD nanopillars and N-UNCD nanograss structures. The $E_{0}$ value of $11.6 \mathrm{~V} / \mu \mathrm{m}$ and the $J_{\mathrm{e}}$ of $3.50 \mathrm{~mA} / \mathrm{cm}^{2}$ at an applied field of $30 \mathrm{~V} / \mu \mathrm{m}(\beta=3041)$ are attained for UNCD nanopillars (curve I). The N-UNCD nanograss structures show even better EFE properties, viz, an $E_{0}$ value of $2.6 \mathrm{~V} / \mu \mathrm{m}$ with a current density of $J_{\mathrm{e}}=2.38 \mathrm{~mA} / \mathrm{cm}^{2}$ at an applied voltage of 5.8 $\mathrm{V} / \mu \mathrm{m}(\beta=3871)$. The superior EFE properties of N-UNCD nanograss structures are apparently a result from the unique granular structure of the N-UNCD grains, i.e., they are needlelike grains encased with few layer of graphite materials. ${ }^{58}$ Table 3 summarized the EFE characteristics $\left(E_{0}, J_{\mathrm{e}}\right.$, and $\left.\beta\right)$ of all

Table 3. Electron Field Emission (EFE) Properties of Different Diamond Nanostructures

\begin{tabular}{lccr}
\multicolumn{1}{c}{ sample } & $\begin{array}{c}E_{0} \\
(\mathrm{~V} / \mu \mathrm{m})\end{array}$ & $J_{\mathrm{e}}\left(\mathrm{mA} / \mathrm{cm}^{2}\right) @$ applied field & $\begin{array}{r}\beta \\
(\mathrm{V} / \mu \mathrm{m})\end{array}$ \\
factor \\
MCD nanocones & 35.0 & $0.91 @ 200$ & 259 \\
NCD nanotips & 16.2 & $2.50 @ 38$ & 347 \\
UNCD nanopillars & 11.6 & $3.95 @ 30$ & 3041 \\
N-UNCD & 2.6 & $2.38 @ 5.8$ & 3891 \\
$\quad$ nanograss & & & \\
\hline
\end{tabular}

these diamond nanostructures. The EFE properties achieved for N-UNCD nanograss are superior to most of the EFE properties of the diamond nanostructures, which had been reported in the literature (see Table S1 in the Supporting Information).

On the other hand, the enhancement in single photon emission of the NV center has been reported from diamond nanowires, which is fabricated from single-crystalline diamond. ${ }^{18-20} \mathrm{PL}$ is the most practical measurement for characterizing the presence of active NV centers. Figure 10a shows the PL spectra of MCD nanocones (curve I) and NCD nanotips (curve II) of the 30-min-etched diamond sample. Notably, the intensity of PL lines is many orders of magnitude larger than those for pristine MCD and NCD films (figure not shown). The characteristic zero-phonon-line (ZPL) of neutral 


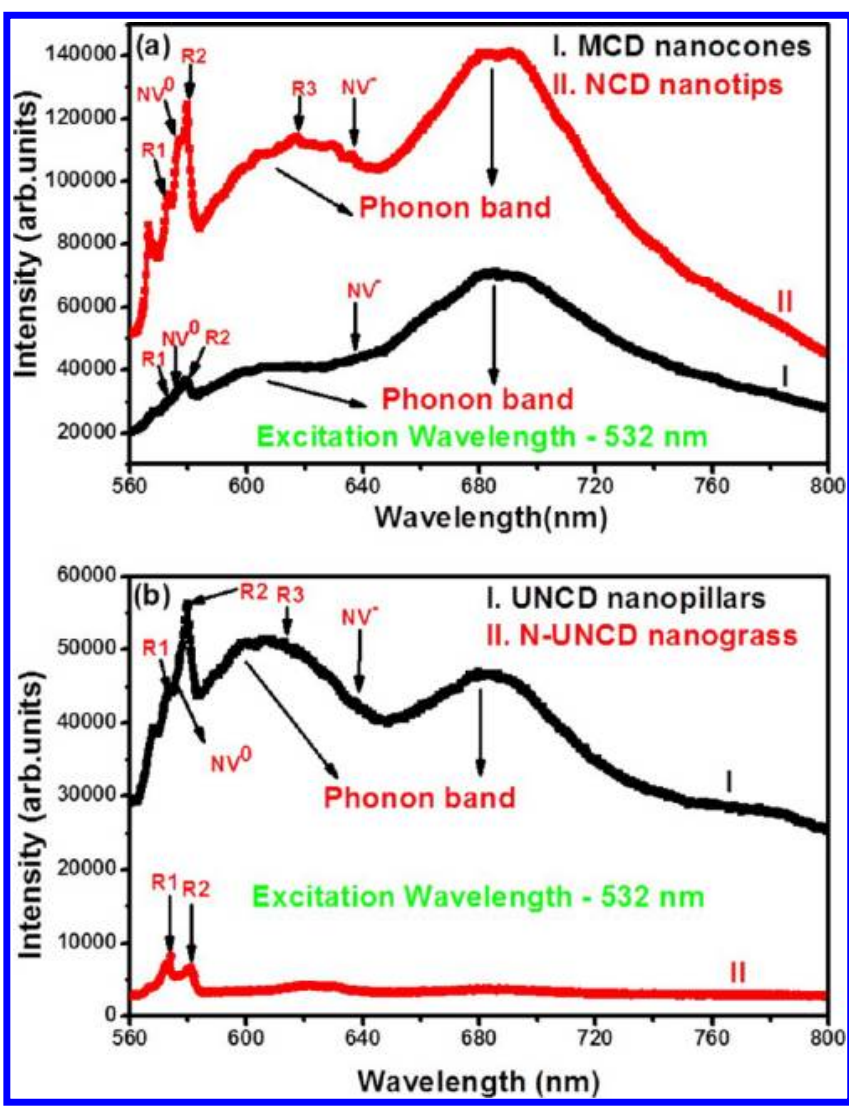

Figure 10. Photoluminensence (PL) spectra of (a) MCD nanocones (curve I) and NCD nanotips (curve II) and (b) those of UNCD nanopillars (curve I) and N-UNCD nanograss (curve II) structure, showing the presence of $\mathrm{NV}$ color centers beside the Raman resonance peaks (R1 and R2).

$\mathrm{NV}$ center $\left(\mathrm{NV}^{0}\right)$ at the wavelength of $575.0 \mathrm{~nm}$ and $\mathrm{ZPL}$ of $\mathrm{NV}^{-}$at the wavelength of $637 \mathrm{~nm}$ with wide phonon side bands confirms the existence of NV centers in the MCD and NCD nanostructures. ${ }^{18}$ The characteristic feature of the diamond has been demonstrated in the NV center PL spectrum, showing the first-order Raman scattering lines of diamond and $\mathrm{sp}^{2}$ carbon for MCD nanocones, NCD nanotips at wavelengths of 573.0 $\mathrm{nm}$ (R1) and $578 \mathrm{~nm}$ (R2). The second-order Raman scattering line has been depicted at the wavelength of 617.0 $\mathrm{nm}$ (denoted as R3). ${ }^{59,60}$ The $\mathrm{NV}^{-}$centers in the nanostructures are created during the CVD growth process of pristine diamond films. The existence of very small amounts of nitrogen in the CVD chamber is the cause for the formation of $\mathrm{NV}$ centers in the diamond films, although we do not add any external source of nitrogen. The increase in PL intensities observed for NCD nanotips, compared to those for MCD nanocones, is due to the high density of nanotips exhibit in the micrometer measurement area. In contrast, Figure $10 \mathrm{~b}$ shows the PL spectra of UNCD nanopillars and N-UNCD nanograss structures of 30-min-etched samples. The UNCD nanopillar structure (curve I, Figure 9b) shows the characteristic ZPL of $\mathrm{NV}^{0}$ and $\mathrm{NV}^{-}$centers, in addition to the phonon sideband and high-intensity characteristic first-order Raman peaks of diamond ( $\mathrm{R} 1$ and $\mathrm{R} 2)^{18,59,60}$ In the case of N-UNCD nanograss structures, the first-order Raman peak of diamond and $\mathrm{sp}^{2}$-bonded carbon are observed (R1 and $\mathrm{R} 2$ ), but no $\mathrm{NV}$ center luminescence is observed (curve II, Figure 10b).
The PL intensity of UNCD nanopillars is lower in comparison to that of the nanostructures of MCD and NCD. Nevertheless, we observe the NV center luminescence from UNCD with an ultrasmall grain size of $5 \mathrm{~nm}$, contrary to the observations that luminescence can only originate from primary diamond particles exceeding $30 \mathrm{~nm}$ in size. ${ }^{61}$ In contrast, the NUNCD nanograss does not show any significance of the NV center. The probable cause for this phenomenon is that the presence of nanographite phase encasing the nanosized diamond grains might suppress the activity of $\mathrm{NV}$ center through an "optical quenching" mechanism. ${ }^{61,62}$ Restated, enhanced PL is observed from nanostructures that is presumably due to the surface effect ${ }^{63}$ and the annealing process that performed before the RIE process.

\section{CONCLUSION}

Various types of diamond nanostructures were fabricated from different morphological diamond films using a self-biased reactive-ion etching (RIE) process with dewetted Au nanodots as an etching mask. The Au nanodots are attained by annealing a thin gold film $4 \mathrm{~nm}$ thick at $700{ }^{\circ} \mathrm{C}$ under vacuum for $30 \mathrm{~min}$. The different morphological diamond films are systematically etched using $95 \% \mathrm{O}_{2} / 5 \% \mathrm{CF}_{4}$ reactive gases for 10,20 , and 30 $\mathrm{min}$. The high aspect ratio of the nanostructures is developed from the different types of diamond films for the etching time of $30 \mathrm{~min}$. The etching mechanism is explained from the reactive ions of the etching plasma in which the reactive ions are measured using in situ optical emission spectroscopy (OES) studies. Our investigations reveal that nanostructuring of diamond is a function of the initial diamond morphology, the phase composition of the diamond, the mask size, and the etching time. The enhanced field emission properties are observed for N-UNCD nanograss, which are due to the high aspect ratio and the formation of a graphitic phase. In contrast, high-intensity photoluminesence (PL) is observed from the $\mathrm{NV}^{0}$ and $\mathrm{NV}^{-}$color centers of NCD nanotips. As a consequence, the diamond nanostructures have great potential to be applied as electron field emitters or single photon sources. The necessary characteristics can be optimized through the control of morphology of nanostructures that, in turn, can be achieved by proper choice of initial granular structures of diamond films.

\section{ASSOCIATED CONTENT}

\section{Supporting Information}

FESEM images of the RIE-performed MCD, NCD, UNCD and $\mathrm{N}-\mathrm{UNCD}$ samples for the etching times of 10 and $20 \mathrm{~min}$. The time-dependent etching of the different morphological diamond films with gold mask has been revealed systematically. Typical SEM-EDS profile collected from 30-min-etched samples for examining the existence of a gold nanodot mask; the results disclose the absence of a gold mask. This material is available free of charge via the Internet at http://pubs.acs.org.

\section{AUTHOR INFORMATION}

\section{Corresponding Author}

*E-mail: kcleou@ess.nthu.edu.tw (K.C.L), inanlin@mail.tku. edu.tw (I.N.L).

\section{Author Contributions}

The manuscript was written through contributions of all authors. All authors have given approval to the final version of the manuscript. 


\section{Notes}

The authors declare no competing financial interest.

\section{ACKNOWLEDGMENTS}

The authors would like to thank the National Science Council, Republic of China, for the support of this research (through Project No. NSC 101-2112-M-032-002).

\section{REFERENCES}

(1) Strother, T.; Cai, W.; Xinsheng, Z.; Robert, H. J.; Smith, L. M. J. Am. Chem. Soc. 2000, 122, 1205-1209.

(2) Huang, H. W.; Kao, C. C.; Chu, J. T.; Wang, W. C.; Lu, T. C.; Kuo, H. C.; Wang, S. C.; Yu, C. C.; Kuo, S. Y. Mater. Sci. Eng., B 2007, 136, 182-186.

(3) Li, G.; Robyn, L. W.; Baolai, L.; Marta, P.; Sergey, P.; Mike, J.; Niti, G.; Mantu, K.H.; Diana, L. H.; Mark, S. G.; Suneel, K.; Robert, F. H. Nano Lett. 2009, 9, 2223-2228.

(4) Hashimoto, K.; Ito, K.; Ishlmori, Y. Anal. Chem. 1994, 66, 38303833.

(5) Huang, H. W.; Kao, C. C.; Hsueh, T. H.; Yu, C. C.; Lin, C. F.; Chu, J. T.; Kuo, H. C.; Wang, S. C. Mater. Sci. Eng., B 2004, 113, 125129.

(6) Field, J. E., Ed. The Properties of Diamond; Academic Press: London, 1979; pp 4-22.

(7) Nebel, C. E.; Rezek, B.; Shin, D.; Uetsuka, H.; Yang, N. J. Phys. D: Appl. Phys. 2007, 40, 6443-6466.

(8) Dieter, M. G. Annu. Rev. Mater. Sci. 1999, 29, 211-259.

(9) Zhu, W.; Bower, C.; Kochanski, G. P.; Jin, S. Solid- State Electrochem. 2001, 45, 921-928.

(10) Madaleno, J. C.; Singh, M. K.; Titus, E.; Cabral, G.; Grácio, J.; Pereira, L. Appl. Phys. Lett. 2008, 92, 023113.

(11) Zhu, W.; Kochanski, G. P.; Jin, S. Science 1998, 282, 1471-1473.

(12) Yamada, T.; Nebel, C. E.; Rezek, B.; Takeuchi, D.; Fujimori, N. Appl. Phys. Lett. 2005, 87, 234107.

(13) Koenigsfeld, N.; Kalish, R. Appl. Phys. Lett. 2003, 82, 46874689.

(14) Wang, Q.; Wang, Z. L. Appl. Phys. Lett. 2006, 89, 063105.

(15) Rosolen, J. M.; Tronto, S.; Marchesin, M. S.; Almeida, E. C.; Ferreeira, N. G.; Poa, C. H. P.; Silva, S. R. P. Appl. Phys. Lett. 2006, 88, 083116.

(16) Tzeng, Y. F.; Lee, Y. C.; Lee, C. Y.; Lin, I. N.; Chiu, H. T. Appl. Phys. Lett. 2007, 91, 06311.

(17) Lu, X.; Yang, Q.; Xiao, C.; Hirose, A.; Tiedje, T. J. Phys. D: Appl. Phys 2007, 40, 4010-4014.

(18) Pezzagna, S.; Rogalla, D.; Wildanger, D.; Meijer, J.; Zaitsev, A. New J. Phys. 2011, 13, 035024.

(19) Babinec, T. M.; Hausmann, B. J. M.; Khan, M.; Zhang, Y.; Maze, J. R.; Hemmer, P. R.; Marko, L. Nat. Nanotechnol. 2010, 5, 195-199.

(20) Rabeau, J. R.; Stacey, A.; Rabeau, A.; Prawer, S.; Jelezko, F.; Mirza, I.; Wrachtrup, J. Nano Lett. 2007, 7, 3433-3437.

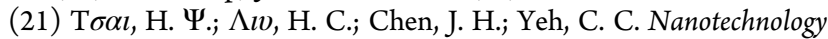
2011, 22, 235301.

(22) Zhang, W. J.; Meng, X. M.; Chan, C. Y.; Wu, Y.; Bello, I.; Lee, S. T. Appl. Phys. Lett. 2003, 82, 2622-2624.

(23) Zhang, W. J.; Wu, Y.; Cha, C. Y.; Wong, W. K.; Meng, X. M.; Bello, I.; Lifshitz, Y.; Lee, S. T. Diamond. Relat. Mater. 2004, 13, 10371043.

(24) Zou, Y. S.; Ma, K. L.; Zhang, W. J.; Ye, Q.; Yao, Z. Q.; Chong, Y. M.; Lee, S. T. Diamond. Relat. Mater. 2007, 16, 1208-1212.

(25) Zhang, W. J.; Wu, Y.; Wong, W. K.; Meng, X .M.; Chan, C. Y.; Bello, I.; Lifshitz, Y.; Lee, S. T. Appl. Phys. Lett. 2003, 83, 3365-3367.

(26) Ando, Y.; Nishibayashi, Y.; Sawabe, A. Diamond. Relat. Mater. 2004, 13, 633-637.

(27) Zou, Y. S.; Yang, Y.; Zhang, W. J.; Chong, Y. M.; He, B.; Bello, I.; Lee, S. T. Appl. Phys. Lett. 2008, 92, 053105.

(28) Yang, N.; Uetsuka, H.; Williams, O. A.; Osawa, E.; Tokuda, N.; Nebel, C. E. Phys. Status Solidi A 2009, 206, 2048-2056.
(29) Smirnov, W.; Kriele, A.; Yang, N.; Nebel, C. E. Diamond. Relat. Mater. 2010, 19, 186-189.

(30) Hausmann, B. J. M.; Khan, M.; Zhang, Y.; Babinec, T. M.; Martinick, K.; McCutcheon, M.; Hemmer, P. R.; Lončar, M. Diamond. Relat. Mater. 2010, 19, 621-629.

(31) Okuyama, S.; Matsushita, S. I.; Fujishima, A. Langmuir 2002, 18, 8282-8287.

(32) Lu, C.; Li, Y.; Tian, S.; Li, W.; Li, J.; Changzhi, G. Microelectron. Eng. 2011, 88, 2319-2321.

(33) Wang, X.; Ocola, L. E.; Divan, R. S.; Sumant, A. V. Nanotechnology 2012, 23, 075301.

(34) Szunerits, S.; Coffinier, Y.; Galopin, E.; Brenner, J.; Boukherroub, R. Electrochem. Commun. 2010, 12, 438-441.

(35) Lin, J. Y.; Li, Z. C.; Chen, C. Y.; Chou, L. J.; Hwang, J. C.; Kou, C. S. Diamond. Relat. Mater. 2011, 20, 922-926.

(36) Okamoto, H.; Massalski, T. B. J. Phase. Equil. 1984, 5, 378-379.

(37) Takagi, D.; Kobayashi, Y.; Hibino, H.; Suzuki, S.; Homma, Y. Nano Lett. 2008, 8, 832-835.

(38) Tran, D. T.; Fansler, C.; Grotjohn, T. A.; Reinhard, D. K.; Asmussen, J. Diamond. Relat. Mater. 2010, 19, 778-782.

(39) Fowler, R. H.; Nordheim, L. Proc. R. Soc. London, Ser. A 1928, 119, 173-181.

(40) May, P. W.; Ashfold, M. N. R.; Mankelevich, Y. A. J. Appl. Phys. 2007, 101, 053115

(41) Sankaran, K. J.; Joseph, P. T.; Chen, H. C.; Tai, N. H.; Lin, I. N. Diamond. Relat. Mater. 2011, 20, 232-237.

(42) Hickey, D.; Jones, K. S.; Elliman, R. G. Diamond. Relat. Mater. 2009, 18, 1353-1359.

(43) Sankaran, K. J.; Kurian, J.; Chen, H. C.; Dong, C. L.; Lee, C. Y.; Tai, N. H.; Lin, I. N. J. Phys. D: Appl. Phys. 2012, 45, 365303.

(44) Buckley, R. G.; Moustakas, T. D.; Ye, L.; Varon, J. J. Appl. Phys. 1989, 66, 3595-3599.

(45) Ferrari, A. C.; Robertson, J. Phys. Rev. B 2001, 63, 121405.

(46) Nishibayashi, Y.; Ando, Y.; Furuta, H.; Kobashi, K.; Meguro, K.; Imai, T.; Hirao, T.; Oura, K. Mol. Cryst. Liq. Cryst. 2002, 386, 183188.

(47) Teii, K.; Hori, M.; Goto, T. J. Electrochem. Soc. 2001, 148 (2), G55-G58.

(48) Wang, Q.; Li, J. J.; Jin, A. Z.; Wang, Z. L.; Xu, P.; Gu, C. Z. Diamond Relat. Mater. 2006, 15, 866-869.

(49) Teii, K.; Hori, M.; Goto, T. J. Vac. Sci. Technol. A 2000, 18 (6), 2779-2784.

(50) Prawer, S.; Kalish, R. Phys. Rev. B 1995, 51, 15711-15722.

(51) Li, J. J.; Zheng, W. T.; Wu, H. H.; Sun, L.; Gu, G. G.; Bian, H. J.; Lu, X. Y.; Jin, Z. S. J. Phys. D: Appl. Phys. 2011, 36, 2001-2005.

(52) Chau, T. T.; Kao, K. C. J. Vac. Sci. Technol. B 1996, 14, 527532.

(53) Shabushnig, J. G.; Demko, P. R.; Savage, R. N. Mater. Res. Soc. Symp. Proc. 1985, 38, 77-84.

(54) Lieberman, M. A.; Lichtenberg, A. J. Principles of Plasma Discharges and Materials Processing, 2nd Edition; John Wiley \& Sons: Hoboken, NJ, 2005; p 279.

(55) Ando, Y.; Nishibayash, Y.; Kobashi, K.; Hirao, T.; Oura, K. Diamond Relat. Mater. 2002, 11, 824-827.

(56) Yoon, J. H.; Lee, W. S.; Park, J. K.; Hwang, G. W.; Baik, Y. J.; Seong, T. Y.; Jeong, J. H. J. Appl. Phys. 2010, 107, 044313.

(57) Xie, H. D.; Sun, B.; Zhu, X. M.; Liu, Y. J. Int. J. Plasma Environ. Sci. Technol. 2009, 3, 39-42.

(58) Sankaran, K. J.; Kunuku, S.; Lou, S. C.; Kurian, J.; Chen, H. C.; Lee, C. Y.; Tai, N. H.; Leou, K. C.; Chen, C.; Lin, I. N. Nanoscale Res. Lett. 2012, 7, 522.

(59) Kurtsiefer, C.; Mayer, S.; Zarda, P.; Weinfurter, H. Phys. Rev. Lett. 2000, 85, 290-293.

(60) Vlasov, I. I.; Shenderova, O.; Turner, S.; Lebedev, O. I.; Basov, A. A.; Sildos, I.; Rähn, M.; Shiryaev, A. A.; Tendeloo, G. V. Small 2010, 6, 687-694.

(61) Smith, B. R.; Lnglis, D. W.; Sandnes, B.; Rabeau, J. R.; Zvyagin, A. V.; Gruber, D.; Noble, C. J.; Robert, V.; Ōlsawa, E.; Plakhotnik, T. Small 2009, 5, 1649-1653. 
(62) Chen, L. H.; Lim, T. S.; Chang, H. C. J. Opt. Soc. Am. B 2012, 29, 2309-2313.

(63) Liao, Z. M.; Zhang, H. Z.; Zhou, Y. B.; Xu, J.; Zhang, J. M.; Yu, D.P . Phys. Lett. A 2008, 372, 4505-4509. 